\title{
Effect of Europium Substitution on Thermoelectric Properties of Noble-Metal Silicon Clathrates with $\mathrm{Ba}_{8-x} \mathrm{Eu}_{x} \mathrm{Cu}_{y} \mathrm{Si}_{46-y}$ Nominal Compositions
}

\author{
H. Anno ${ }^{1}$, K. Okita ${ }^{1}$, K. Koga ${ }^{2}$, S. Harima ${ }^{1}$, T. Nakabayashi ${ }^{1}$, M. Hokazono ${ }^{1}$ and K. Akai ${ }^{3}$ \\ ${ }^{1}$ Department of Electrical Engineering, Tokyo University of Science, Yamaguchi, Sanyoonoda 756-0884, Japan \\ ${ }^{2}$ Kobelco Research Institute, Inc., Kobe 651-0073, Japan \\ ${ }^{3}$ Media and Information Technology Center, Yamaguchi University, Yamaguchi 753-8511, Japan
}

The effect of the substitution of a rare-earth element for a guest element on the electronic and thermoelectric properties is investigated for clathrates with the nominal composition $\mathrm{Ba}_{8-x} \mathrm{Eu}_{x} \mathrm{Cu}_{y} \mathrm{Si}_{46-y}(x=0,1,2 ; y=4,5,6)$. The Seebeck coefficient and the electrical conductivity of the rare-earth-substituted $\mathrm{Ba}_{8-x} \mathrm{Eu}_{x} \mathrm{Cu}_{y} \mathrm{Si}_{46-y}$ samples are consistent with $n$-type conduction and metal-like behavior. The Hall carrier mobility of $\mathrm{Ba}_{8-x} \mathrm{Eu}_{x} \mathrm{Cu}_{6} \mathrm{Si}_{40}$ at room temperature decreases with increasing Eu substitution. The conduction band effective mass of rare-earth-substituted $\mathrm{Ba}_{8-x} \mathrm{Eu}_{x} \mathrm{Cu}_{6} \mathrm{Si}_{40}(x=1,2)$ is experimentally estimated to be larger than that of $\mathrm{Ba}_{8} \mathrm{Cu}_{6} \mathrm{Si}_{40}$. On the basis of ab initio electronic structure calculations for $\mathrm{Ba}_{6} \mathrm{Eu}_{2} \mathrm{Cu}_{6} \mathrm{Si}_{40}$ and $\mathrm{Ba}_{8} \mathrm{Cu}_{6} \mathrm{Si}_{40}$, it is deduced that the conduction band edges of $\mathrm{Ba}_{8} \mathrm{Cu}_{6} \mathrm{Si}_{40}$ are modified by the substitution of $\mathrm{Eu}$ for the guest atom $\mathrm{Ba}$, resulting in an increase in the density-of-states effective mass, which is consistent with the experimental result. [doi:10.2320/matertrans.E-M2012816]

(Received November 20, 2011; Accepted April 25, 2012; Published June 20, 2012)

Keywords: rare-earth element, europium, clathrate, silicon, guest substitution, electronic structure, effective mass, Seebeck coefficient, Hall mobility

\section{Introduction}

Group 14 ( $\mathrm{Si}, \mathrm{Ge}, \mathrm{Sn})$ clathrates with the type-I structure (space group $P m \overline{3} n$ ) have recently received considerable attention as novel thermoelectric materials with potential applicability to the phonon glass electron crystal concept for high-temperature applications. These materials are suitable for such applications because they possess extremely low thermal conductivity and good electrical properties. ${ }^{1-3)}$ The low thermal conductivity of group 14 clathrates, which is similar to the thermal conductivity of glass, is attributed to the guest-host interactions whereby the localized guest vibrations interact strongly with the acoustic modes of the framework (host), whereas the good electronic conduction is due to the covalent $s p^{3}$ hybridization of the framework. $\left.{ }^{2,3}\right)$ Thus, in order to optimize the thermoelectric nature of the clathrates, it is essential to understand the relationship between the guest-host interactions and the thermoelectric properties.

Recently, the optimization of the electronic band structure of group 14 clathrates for use as thermoelectric materials has been evaluated based on a study of the effect of the substitution of transition metal elements for host elements on the thermoelectric properties of the clathrates. ${ }^{4-19)}$ Anno et al. ${ }^{4,5,7,8,15)}$ systematically investigated the thermoelectric properties of Ge-clathrates containing transition metal elements $(\mathrm{Cu}, \mathrm{Ag}, \mathrm{Au}, \mathrm{Pd}, \mathrm{Pt})$ in the host. They found that the substitution of some transition metal elements $(\mathrm{Pd}, \mathrm{Pt}$, $\mathrm{Ag}, \mathrm{Au})$ at the $6 \mathrm{c}$ site for the host element causes an enhancement in the effective mass, resulting in an increased Seebeck coefficient. Akai et al. ${ }^{6,9,11)}$ provided a detailed explanation of the effect of the substitution of transition metal elements for the host element from the viewpoint of firstprinciples calculations. Jaussud et al. ${ }^{13)}$ reported that $\mathrm{Ba}_{8} \mathrm{Au}_{x-}$ $\mathrm{Si}_{46-x}(x=5.4,5.9)$ exhibits $\mathrm{n}$ - and p-type behavior, as is the case for Ge compounds. ${ }^{8)}$
The effect of guest substitution on the thermoelectric properties has also been recently investigated in $\mathrm{Ba}_{6} \mathrm{Eu}_{2} \mathrm{Cu}_{4} \mathrm{Si}_{42},{ }^{20}$ ) $\mathrm{Ba}_{8-x} \mathrm{Eu}_{x} \mathrm{Au}_{6} \mathrm{Ge}_{40},{ }^{21)} \mathrm{Eu}_{2} \mathrm{Ba}_{7} \mathrm{Al}_{13} \mathrm{Si}_{33},{ }^{22)} \mathrm{Eu}_{x} \mathrm{Ba}_{8-x} \mathrm{Al}_{14} \mathrm{Si}_{31},{ }^{23)}$ $\mathrm{Yb}_{x} \mathrm{Ba}_{8-x} \mathrm{Ga}_{16} \mathrm{Ge}_{30},{ }^{24)} \mathrm{Ba}_{6} \mathrm{Eu}_{2} \mathrm{AuGa}_{x} \mathrm{Si}_{45-x}{ }^{25)}$ and $\mathrm{Ba}_{8-x} \mathrm{Eu}_{x^{-}}$ $\mathrm{Ga}_{16} \mathrm{Si}_{30}$ systems. ${ }^{26)}$ In $\mathrm{Ba}_{8-x} \mathrm{Eu}_{x} \mathrm{Au}_{6} \mathrm{Ge}_{40}$ and $\mathrm{Ba}_{8-x} \mathrm{Eu}_{x} \mathrm{Ga}_{16^{-}}$ $\mathrm{Si}_{30}$ compounds, it was found that the substitution of $\mathrm{Eu}$ for Ba guest atoms reduces the lattice thermal conductivity. ${ }^{21,26)}$ The lattice thermal conductivity of $\mathrm{Yb}_{x} \mathrm{Ba}_{8-x} \mathrm{Ga}_{16} \mathrm{Ge}_{30}$ was also substantially lower than that of $\mathrm{Ba}_{8} \mathrm{Ga}_{16} \mathrm{Ge}_{40}$, resulting in an improved thermoelectric figure of merit, $Z T^{24)}$ From the theoretical perspective, Akai et al. ${ }^{9)}$ and Koga et al. ${ }^{27)}$ studied the effect of the substitution of rare-earth elements for $\mathrm{Ba}$ guest atoms on the electronic structure and carrier transport properties of these systems. Based on their results, modification of the conduction band edges at the $\mathrm{X}$ point is induced by the substitution of $\mathrm{Eu}$ and $\mathrm{Yb}$ into the $2 \mathrm{a}$ site inside the smaller cage, leading to an enhanced effective mass. The empirical data for the $\mathrm{Ba}_{8-x} \mathrm{Eu}_{x} \mathrm{Au}_{6} \mathrm{Ge}_{40}{ }^{21)}$ and $\left.\mathrm{Ba}_{6} \mathrm{~A}_{2} \mathrm{AuGa}_{13} \mathrm{Si}_{32}(\mathrm{~A}=\mathrm{Sr}, \mathrm{Eu})^{25}\right)$ systems were consistent with the theoretical evaluations. The strength of the interaction of the guest atom at the 2a site with the framework was explained in terms of the degree of the hybridization states between the guest ( $\mathrm{Eu}$ or $\mathrm{Yb})$ and the framework.

In this study, we extend the study of the effects of guest substitution to various silicon clathrates, including transition metal clathrates, to evaluate empirically the modification of the electronic structure by guest substitution. In this study, we focus on the effect of substituting $\mathrm{Ba}$ at the $2 \mathrm{a}$ site of the host with $\mathrm{Eu}$ on the electronic structure and the thermoelectric properties of $\mathrm{Ba}_{8-x} \mathrm{Eu}_{x} \mathrm{Cu}_{y} \mathrm{Si}_{46-y}$ clathrates.

\section{Experimental Procedure}

Polycrystalline $\mathrm{Ba}_{8-x} \mathrm{Eu}_{x} \mathrm{Cu}_{y} \mathrm{Si}_{46-y}$ (nominal compositions $x=0,1,2 ; y=4,5,6)$ samples were prepared by using arc melting and spark plasma sintering techniques. The starting 
materials comprised a $\mathrm{Ba}$ ingot $(3 \mathrm{~N}), \mathrm{Eu}$ ingot $(3 \mathrm{~N}), \mathrm{Cu}$ grains $(4 \mathrm{~N})$ and $\mathrm{Si}$ grains $(5 \mathrm{~N}) . \mathrm{Ba}_{8-x} \mathrm{Eu}_{x} \mathrm{Cu}_{y} \mathrm{Si}_{46-y}$ ingots were first prepared by arc melting of the constituent elements (with slightly guest-rich (2.5 at\%) compositions) in an argon atmosphere. The arc molten ingots with $y=4$ were annealed at $1123 \mathrm{~K}$ for $96 \mathrm{~h}$ in flowing argon. The annealed ingots $(y=4)$ and arc molten ingots $(y=5$ and 6$)$ were ground to powder $(<90 \mu \mathrm{m})$ and sintered at $1173-1273 \mathrm{~K}$ and 30 $40 \mathrm{MPa}$ for $60-180 \mathrm{~min}$ in an argon atmosphere to obtain dense samples. Powder X-ray diffraction (XRD) measurements were used to evaluate the crystalline structure of the samples. Electron-probe microanalysis (EPMA) measurements were conducted to determine the chemical composition of the samples.

Measurements of the electrical conductivity $(\sigma)$ and the Seebeck coefficient $(S)$ were performed in the temperature range of $300-900 \mathrm{~K}$. Hall measurements were conducted at room temperature on selected samples with $y=6$ by applying an external magnetic field of $1 \mathrm{~T}$ using the van der Pauw method. The Hall mobility $(\mu)$ was determined from the electrical conductivity $(\sigma)$ and the Hall coefficient $\left(R_{\mathrm{H}}\right)$ using the formula $\mu=\sigma R_{\mathrm{H}}$.

The electronic structures of $\mathrm{Ba}_{8} \mathrm{Cu}_{6} \mathrm{Si}_{40}{ }^{6,9)}$ and $\mathrm{Ba}_{6} \mathrm{Eu}_{2-}$ $\mathrm{Cu}_{6} \mathrm{Si}_{40}$ were calculated by using the full-potential augmented plane waves (FLAPW) plus local orbital (LO) method by utilizing the WIEN2k package. ${ }^{28)}$ The exchange-correlation potential parameterized by PerdewBruke-Enzerhof was used. ${ }^{29)}$ The cutoff energy of the plane waves was $10.1 \mathrm{Ry}$ in $\mathrm{Ba}_{6} \mathrm{Eu}_{2} \mathrm{Cu}_{6} \mathrm{Si}_{40}$. The maximum magnitude of the reciprocal lattice vector $(G)$ that was used in the Fourier expansion of charge density was 14. In this study, the selected muffin-tin sphere radii for $\mathrm{Eu}, \mathrm{Ba}, \mathrm{Si}$ and $\mathrm{Cu}$ were 3.0, 3.0, 2.2 and $2.4 \mathrm{Bohr}$, respectively. In the selfconsistent field (SCF) calculation to solve the Kohn-Sham equation, more than $20 \mathrm{k}$-points were taken in an irreducible Brillouin zone (IBZ) for sampling. The lattice constant and atomic positions calculated by Akai et al. ${ }^{6,9)}$ were used. In the calculation of the band structure of $\mathrm{Ba}_{8-x} \mathrm{Eu}_{x} \mathrm{Cu}_{y} \mathrm{Si}_{46-x}$, we also used the generalized gradient approximation (GGA) and GGA $+U$ methods, where $U$ is used to account for correlation effects in an open atomic-like Eu $4 f$ shell. Spinorbit coupling was also included.

\section{Results and Discussion}

Figures 1(a)-1(c) show the X-ray diffraction patterns of the $\mathrm{Ba}_{8-x} \mathrm{Eu}_{x} \mathrm{Cu}_{y} \mathrm{Si}_{46-y}$ samples. The X-ray diffraction peaks could be indexed to a cubic unit cell corresponding to the type-I clathrate structure, indicating that the type-I clathrate was the major phase of the samples. Weak peaks due to impurity phases were also detected as shown in Fig. 1, and are attributed mainly to unreacted $\mathrm{Si}$ and $\mathrm{Eu}-\mathrm{Cu}-\mathrm{Si}$ phases that became significant as the nominal $\mathrm{Eu}$ and $\mathrm{Cu}$ content increased. Observation of the sample surface using SEM and EPMA provided evidence of a small amount of $\mathrm{Si}$ and $\mathrm{Eu}-$ $\mathrm{Cu}-\mathrm{Si}$ phases, consistent with the XRD measurements. Similar observations of impurity phases were reported for the $\mathrm{Ba}_{8} \mathrm{Cu}_{y} \mathrm{Si}_{46-y}$ (nominal $y=3-8$ ) system. ${ }^{30}$ )

Figure 2 shows the lattice constant $a$ as a function of the nominal $\mathrm{Eu}$ composition $x$ for the $\mathrm{Ba}_{8-x} \mathrm{Eu}_{x} \mathrm{Cu}_{y} \mathrm{Si}_{46-y}$
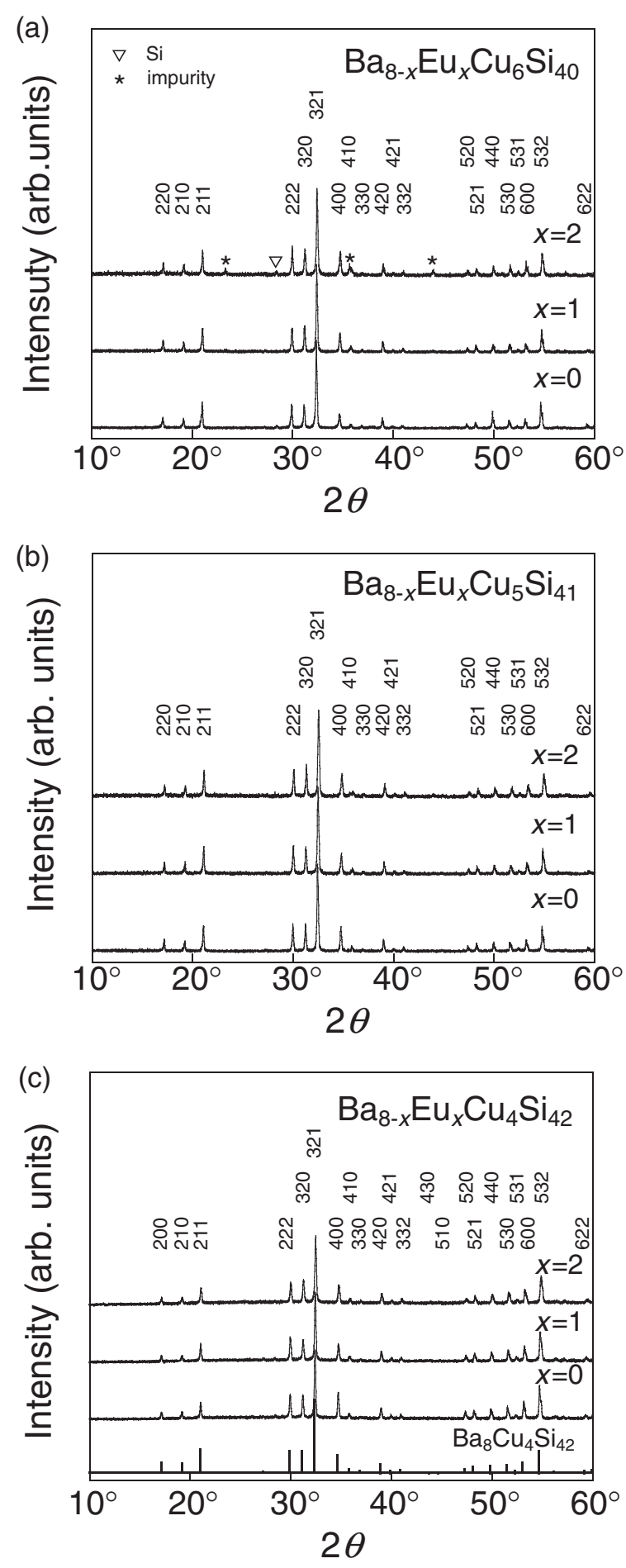

Fig. 1 X-ray diffraction patterns of $\mathrm{Ba}_{8-x} \mathrm{Eu}_{x} \mathrm{Cu}_{y} \mathrm{Si}_{46-y}$ samples.

samples; the lattice constant values of $\mathrm{Ba}_{8} \mathrm{Cu}_{4} \mathrm{Si}_{42}, \mathrm{Ba}_{8} \mathrm{Cu}_{6}$ $\mathrm{Si}_{40}$ and $\mathrm{Ba}_{6} \mathrm{Eu}_{2} \mathrm{Cu}_{4} \mathrm{Si}_{42}$ are also plotted as references. ${ }^{20,30-32)}$ The lattice constant $a$ of the evaluated $\mathrm{Ba}_{8-x} \mathrm{Eu}_{x} \mathrm{Cu}_{y} \mathrm{Si}_{46-y}$ samples decreases monotonically with increasing nominal europium content $x$, and it tends to increase with increasing nominal $\mathrm{Cu}$ composition $y$ for a given nominal $x$. In the $\mathrm{Ba}_{8} \mathrm{Cu}_{y} \mathrm{Si}_{46-y}$ (nominal $y=3-8$ ) system, the lattice constant increases monotonically as the $\mathrm{Cu}$ composition increases from $y=3$ to $y=5$; saturation is achieved for $y>5{ }^{30)}$ The increase in the value of $a$ due to the substitution of $\mathrm{Cu}$ for $\mathrm{Si}$ can be qualitatively explained by the fact that the atomic 


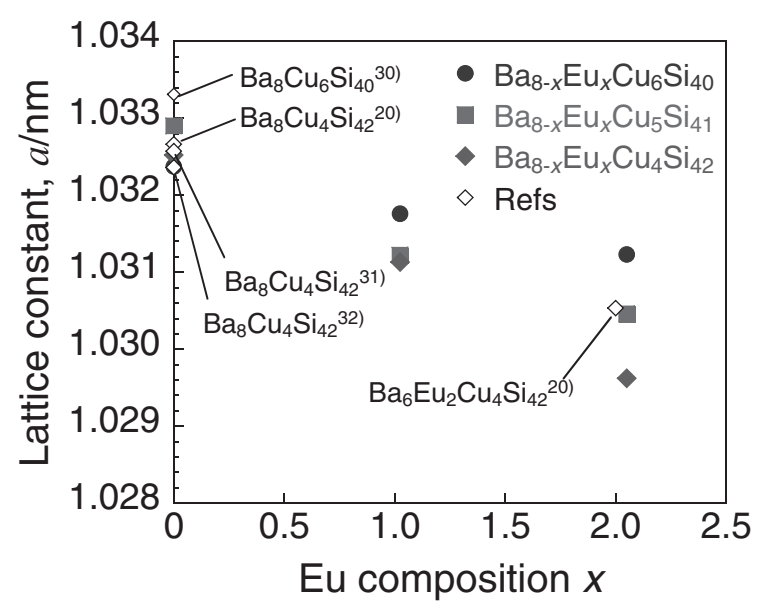

Fig. 2 Lattice constant $a$ as a function of the nominal Eu composition $x$ of $\mathrm{Ba}_{8-x} \mathrm{Eu}_{x} \mathrm{Cu}_{y} \mathrm{Si}_{46-y}$ samples.

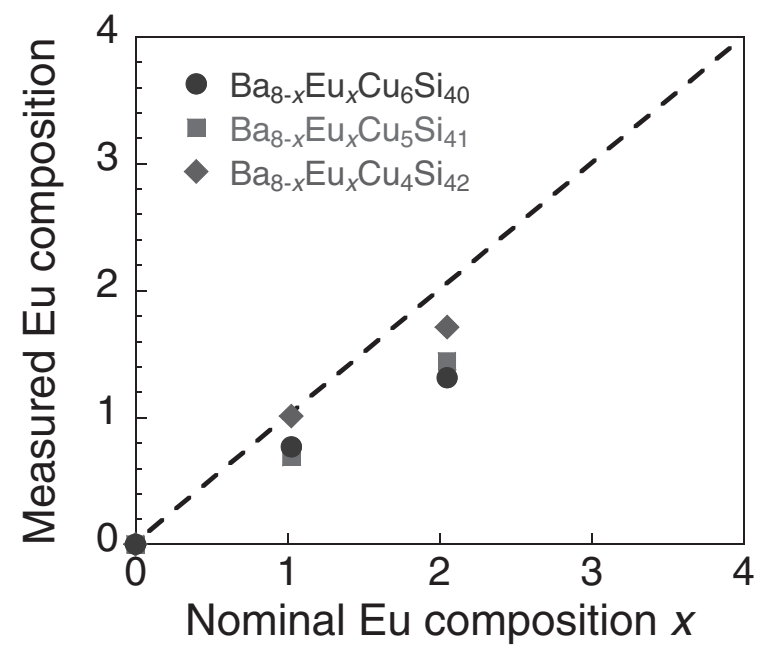

Fig. 3 Eu composition measured by EPMA vs. nominal Eu composition $x$ for $\mathrm{Ba}_{8-x} \mathrm{Eu}_{x} \mathrm{Cu}_{y} \mathrm{Si}_{46-y}$ samples.

radius of $\mathrm{Cu}(0.135 \mathrm{~nm})$ in tetrahedral covalent bonds is larger than that of $\mathrm{Si}(0.117 \mathrm{~nm}){ }^{33)}$ On the other hand, the reason for the decrease in $a$ upon the substitution of Eu for $\mathrm{Ba}$ guest atoms is rather complicated. The ionic radius of $\mathrm{Eu}^{2+}(0.117 \mathrm{~nm})$ is smaller than that of $\mathrm{Ba}^{2+}(0.135 \mathrm{~nm}){ }^{34)}$ In addition, the EPMA results indicate that the actual $\mathrm{Cu}$ composition deviates from the nominal composition and tends to decrease as the nominal $x$ increases. The decrease in $a$ upon the substitution of Eu for Ba plausibly originates from these sources.

As shown in Fig. 3, the experimental Eu composition $x$ on the clathrate phase of the samples (measured using EPMA) increases with increasing nominal Eu composition; however, the measured $\mathrm{Eu}$ composition is less than the nominal composition. On the basis of EPMA, the solubility limits of the Eu guest were estimated to be $x=1.7$ (nominal $y=4$ ), $x=1.4$ (nominal $y=5$ ) and $x=1.3$ (nominal $y=6$ ) in the $\mathrm{Ba}_{8} \mathrm{Cu}_{y} \mathrm{Si}_{46-y}$ system.

Figures 4(a) and 4(b) show the temperature dependence of the electrical conductivity and the Seebeck coefficient for the $\mathrm{Ba}_{8-x} \mathrm{Eu}_{x} \mathrm{Cu}_{y} \mathrm{Si}_{46-y}$ samples, respectively. The temperature dependence of the electrical conductivity and the Seebeck
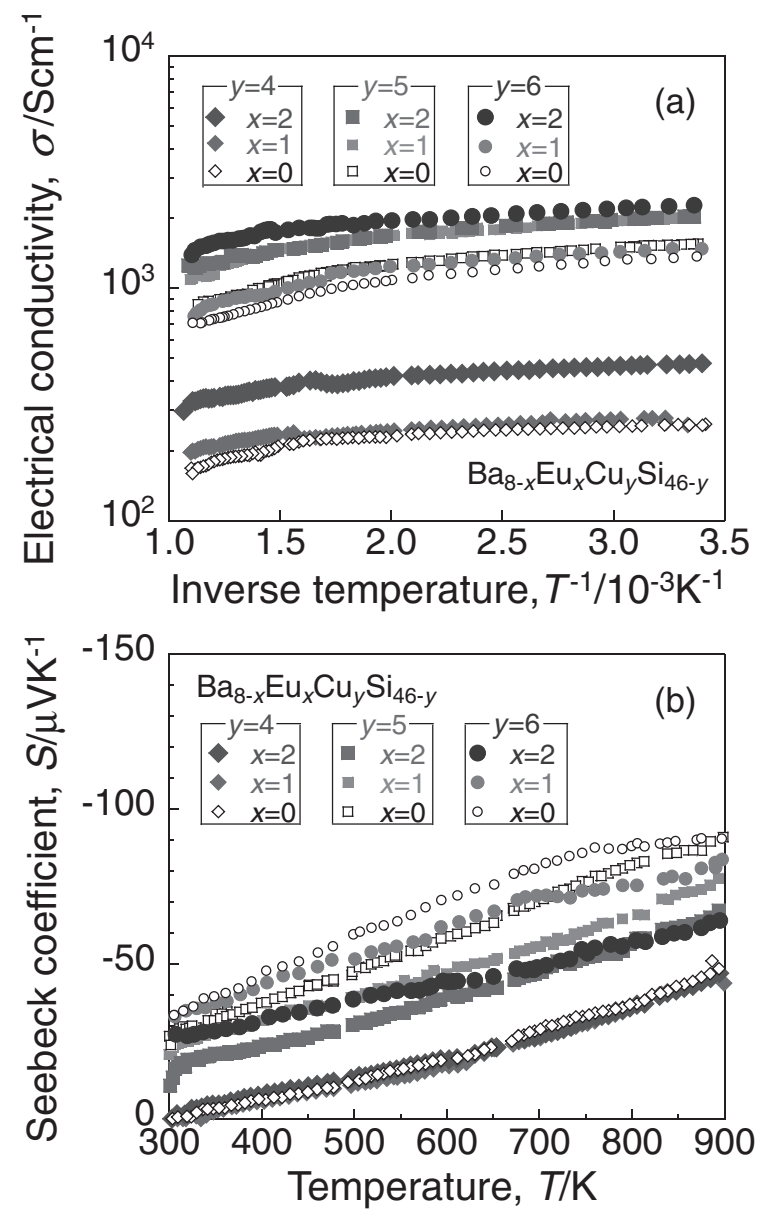

Fig. 4 Temperature dependence of the electrical conductivity $\sigma$ (a) and the Seebeck coefficient $S$ (b) for $\mathrm{Ba}_{8-x} \mathrm{Eu}_{x} \mathrm{Cu}_{y} \mathrm{Si}_{46-y}$ samples.

coefficient indicate metallic behavior, such as those observed in degenerated semiconductors. For $\mathrm{Ba}_{8-x} \mathrm{Eu}_{x} \mathrm{Cu}_{y} \mathrm{Si}_{46-y}(y=$ $5,6)$, the electrical conductivity is as high as $10^{3} \mathrm{~S} / \mathrm{cm}$. In the $\mathrm{Ba}_{8-x} \mathrm{Eu}_{x} \mathrm{Cu}_{y} \mathrm{Si}_{46-y}(y=5,6)$ system, the samples with low electrical conductivity exhibit a large Seebeck coefficient, suggesting that the changes in the electrical conductivity and Seebeck coefficient are attributed to the change in the carrier concentration of the $\mathrm{Ba}_{8-x} \mathrm{Eu}_{x} \mathrm{Cu}_{y} \mathrm{Si}_{46-y}(y=5,6)$ samples. The electrical conductivity of $\mathrm{Ba}_{8-x} \mathrm{Eu}_{x} \mathrm{Cu}_{4} \mathrm{Si}_{42}$ is much smaller than that of $\mathrm{Ba}_{8-x} \mathrm{Eu}_{x} \mathrm{Cu}_{y} \mathrm{Si}_{46-y}(y=5,6)$ because the density of the sintered $\mathrm{Ba}_{8-x} \mathrm{Eu}_{x} \mathrm{Cu}_{4} \mathrm{Si}_{42}$ samples is relatively small. The small Seebeck coefficient of $\mathrm{Ba}_{8-x} \mathrm{Eu}_{x} \mathrm{Cu}_{4} \mathrm{Si}_{42}$ may be attributed to the high carrier concentration of the samples.

In order to evaluate the effect of the substitution of Eu for $\mathrm{Ba}$ guest atoms on the electronic properties of the materials, we estimated the Hall carrier mobility $\mu$ and the densityof-states (DOS) effective mass $m^{*}$ from a single parabolic band model analysis using acoustic phonon scattering as the dominant scattering mechanism, as described elsewhere. ${ }^{35)}$ The Hall carrier concentration, Hall carrier mobility and the effective mass $m^{*} / m_{0}\left(m_{0}\right.$ : the free electron mass) are plotted in Figs. 5(a), 5(b) and 5(c), respectively, as functions of the measured $\mathrm{Eu}$ composition of the $\mathrm{Ba}_{8-x} \mathrm{Eu}_{x} \mathrm{Cu}_{6} \mathrm{Si}_{40}$ samples. The room-temperature Hall coefficient was negative, in agreement with the sign of the Seebeck coefficient. The $n$-type behavior of the $\mathrm{Ba}_{8-x} \mathrm{Eu}_{x} \mathrm{Cu}_{6} \mathrm{Si}_{40}$ samples is due to 

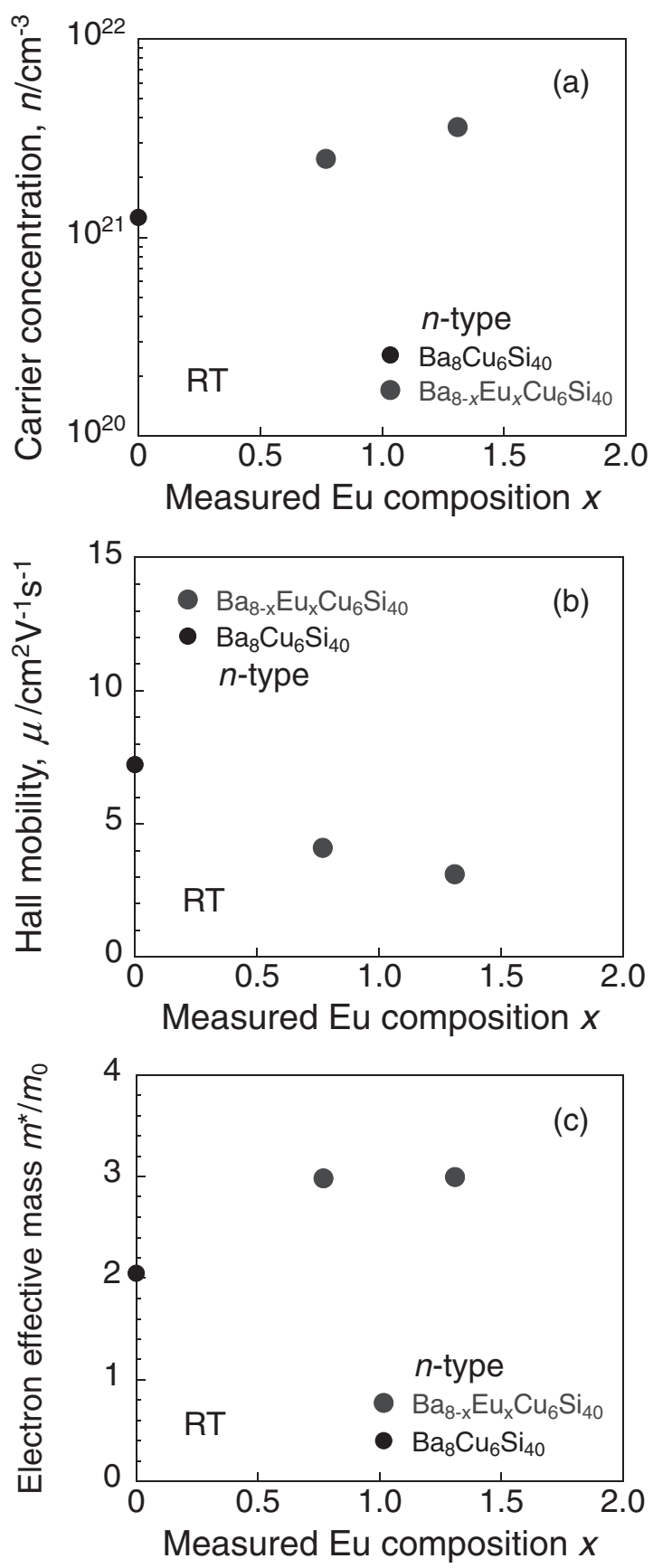

Fig. 5 Hall carrier concentration $n$ (a), Hall carrier mobility $\mu$ (b) and the effective mass $m^{*} / m_{0}$ (c) as functions of measured Eu composition $x$ for $\mathrm{Ba}_{8-x} \mathrm{Eu}_{x} \mathrm{Cu}_{6} \mathrm{Si}_{40}$ samples.

the deviation of the $\mathrm{Cu}$ composition $y$ from the nominal composition, as previously mentioned (at Fig. 2). The Hall carrier concentration is as high as $1.3 \times 10^{21} \mathrm{~cm}^{-3}$ for $\mathrm{Ba}_{8} \mathrm{Cu}_{6} \mathrm{Si}_{40}$ and gradually increases with increasing $\mathrm{Eu}$ concentration for $\mathrm{Ba}_{8-x} \mathrm{Eu}_{x} \mathrm{Cu}_{6} \mathrm{Si}_{40}$. In the case of the $\mathrm{Ba}_{8-x} \mathrm{Eu}_{x} \mathrm{Cu}_{y} \mathrm{Si}_{46-y}(y=4,5)$ samples, the Hall voltage was so small that we were not able to estimate the Hall carrier concentration and the Hall mobility.

We have reported that the conduction band effective mass of $\mathrm{Ba}_{6} \mathrm{~A}_{2} \mathrm{AuGa}_{x} \mathrm{Si}_{45-x}(\mathrm{~A}=\mathrm{Sr}, \mathrm{Eu})$ is enhanced relative to that of $\mathrm{Ba}_{8} \mathrm{Ga}_{x} \mathrm{Si}_{46-x}$ due to modification of the conduction band structure by the substitution of the guest atoms ( $\mathrm{Sr}$ and $\mathrm{Eu}){ }^{25)}$ As was the case for $\mathrm{Ba}_{6} \mathrm{~A}_{2} \mathrm{AuGa}_{x} \mathrm{Si}_{45-x}(\mathrm{~A}=\mathrm{Sr}, \mathrm{Eu})$,
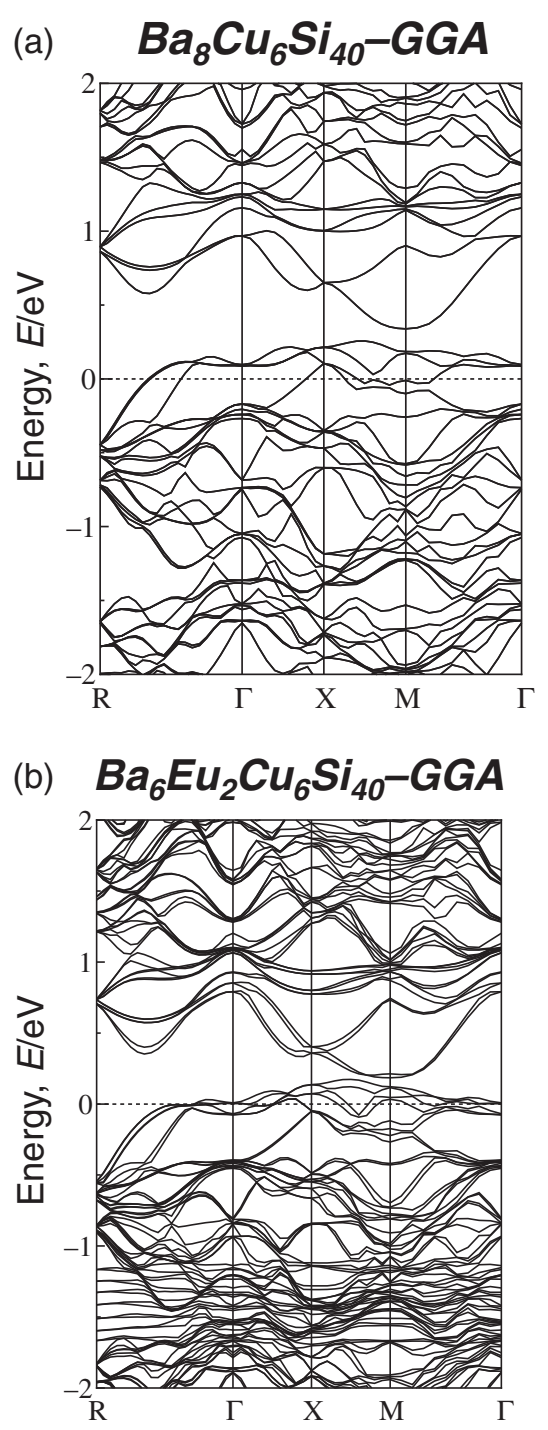

Fig. 6 Electronic band structure near the Fermi energy for $\mathrm{Ba}_{8} \mathrm{Cu}_{6} \mathrm{Si}_{40}$ (a) and $\mathrm{Ba}_{6} \mathrm{Eu}_{2} \mathrm{Cu}_{6} \mathrm{Si}_{40}$ (b).

the effective mass of $\mathrm{Ba}_{8-x} \mathrm{Eu}_{x} \mathrm{Cu}_{6} \mathrm{Si}_{40}$ is estimated in this study and found to be larger than that of $\mathrm{Ba}_{8} \mathrm{Cu}_{6} \mathrm{Si}_{40}$. This observed enhancement in the effective mass is qualitatively consistent with the results of electronic structure calculations for $\mathrm{Ba}_{8} \mathrm{Cu}_{6} \mathrm{Si}_{40}$ and $\mathrm{Ba}_{6} \mathrm{Eu}_{2} \mathrm{Cu}_{6} \mathrm{Si}_{40}$, which are discussed below. The Hall mobility for $\mathrm{Ba}_{8-x} \mathrm{Eu}_{x} \mathrm{Cu}_{6} \mathrm{Si}_{40}$ decreases with increasing $\mathrm{Eu}$ incorporation because of the increased effective mass. Since the amount of impurity phases, as detected by XRD and EPMA, tend to increase as the Eu composition increases, it is probable that the influence of these impurity phases on the Hall mobility is not negligible in $\mathrm{Ba}_{8-x} \mathrm{Eu}_{x} \mathrm{Cu}_{6} \mathrm{Si}_{40}$.

Figures 6(a) and 6(b) respectively show the electronic band structures of $\mathrm{Ba}_{8} \mathrm{Cu}_{6} \mathrm{Si}_{40}$ and $\mathrm{Ba}_{6} \mathrm{Eu}_{2} \mathrm{Cu}_{6} \mathrm{Si}_{40}$. Because the effective mass, which governs the Seebeck coefficient, is determined from the energy dispersion relationship near the band edges, the effect of the substitution of $\mathrm{Eu}$ for $\mathrm{Ba}$ on the electronic structure near the band edges is treated as the point of focus. The overall structure of $\mathrm{Ba}_{6} \mathrm{Eu}_{2} \mathrm{Cu}_{6} \mathrm{Si}_{40}$ is similar to that of $\mathrm{Ba}_{8} \mathrm{Cu}_{6} \mathrm{Si}_{40}$ except for the Eu contribution in the former. The top of the valence band is composed of 
framework $s p^{3}$ states with a flat energy dispersion, and there is a particularly large contribution of the $s$ and $p$ states of the $\mathrm{Si}$ atom to this region. The contribution of $\mathrm{Cu} d$ states to the valence band edge is small because the $\mathrm{Cu} d$ states are located ca. $2-4 \mathrm{eV}$ below the Fermi level. Upon the substitution of $\mathrm{Eu}$ for $\mathrm{Ba}$, the conduction band edge at the $\mathrm{X}$ point shifts to the lower energy side. The bottom of the conduction band near the $M$ point is a flat band in the direction X-M and $\mathrm{M}-\Gamma$, which is derived mainly from the $d$ states of the Eu atoms, the $s, p$ states of the framework $\mathrm{Si}$ atoms, and the $d$ states of the $\mathrm{Cu}$ atoms in $\mathrm{Ba}_{6} \mathrm{Eu}_{2} \mathrm{Cu}_{6} \mathrm{Si}_{40}$. The electronic structure characteristics of $\mathrm{Ba}_{6} \mathrm{Eu}_{2} \mathrm{Cu}_{6} \mathrm{Si}_{40}$ are very similar to that of $\mathrm{Ba}_{6} \mathrm{Eu}_{2} \mathrm{Au}_{6} \mathrm{Ge}_{40}$ reported by Koga et al. ${ }^{27)}$ The calculations for both $\mathrm{Ba}_{8} \mathrm{Cu}_{6} \mathrm{Si}_{40}$ and $\mathrm{Ba}_{6} \mathrm{Eu}_{2}$ $\mathrm{Cu}_{6} \mathrm{Si}_{40}$ show that the Fermi level lies in the valence band, and both of these compounds are p-type conductors. The results of the calculations are consistent with the expectation based on the valence electron counts of the host structure, i.e., it is assumed that both divalent $\mathrm{Ba}$ and $\mathrm{Eu}$ donate two valence electrons to the host structure, and thus, both $\mathrm{Ba}_{8} \mathrm{Cu}_{6} \mathrm{Si}_{40}$ and $\mathrm{Ba}_{6} \mathrm{Eu}_{2} \mathrm{Cu}_{6} \mathrm{Si}_{40}$ have a deficiency of two valence electrons from the total of 184 valence electrons used for covalent bonding of the host structure. As previously alluded to (at Fig. 5 (a)), the n-type behavior of both $\mathrm{Ba}_{8} \mathrm{Cu}_{6} \mathrm{Si}_{40}$ and $\mathrm{Ba}_{6} \mathrm{Eu}_{2} \mathrm{Cu}_{6} \mathrm{Si}_{40}$ samples is attributed to the deviation of the $\mathrm{Cu}$ composition $y$ from the nominal composition. By performing EPMA, the actual $\mathrm{Cu}$ composition was found to be about 4.5 , which corresponds to the valence electron count of $186.5>184$. From the experimental data, it is anticipated that the Fermi level lies in the conduction band for both $\mathrm{Ba}_{8} \mathrm{Cu}_{6} \mathrm{Si}_{40}$ and $\mathrm{Ba}_{6} \mathrm{Eu}_{2} \mathrm{Cu}_{6} \mathrm{Si}_{40}$ samples. Thus, the effect of the substitution of $\mathrm{Eu}$ for $\mathrm{Ba}$ on the conduction band edge is discussed by assuming a rigid band model since the influence of the $\mathrm{Cu}$ composition on the conduction band edge (near the $\mathrm{M}$ point) is small, which was discussed by Akai. ${ }^{11)}$ The conduction band effective mass values estimated from the electronic band structure are $m^{*}{ }_{\mathrm{M}-\mathrm{X}}=0.75 m_{0}$ and $m^{*}{ }_{\mathrm{M}-\Gamma}=0.68 m_{0}$ for $\mathrm{Ba}_{8} \mathrm{Cu}_{6} \mathrm{Si}_{40}$, and $m^{*}{ }_{\mathrm{M}-\mathrm{X}}=1.39 m_{0}$ and $m^{*}{ }_{\mathrm{M}-\Gamma}=0.92 m_{0}$ for $\mathrm{Ba}_{6} \mathrm{Eu}_{2} \mathrm{Cu}_{6} \mathrm{Si}_{40}$.

Figure 7 shows a comparison of DOS near the band edges for the $\mathrm{Ba}_{8} \mathrm{Cu}_{6} \mathrm{Si}_{40}$ and $\mathrm{Ba}_{6} \mathrm{Eu}_{2} \mathrm{Cu}_{6} \mathrm{Si}_{40}$. The DOS near the bottom of the conduction band is larger in the case of $\mathrm{Ba}_{6} \mathrm{Eu}_{2} \mathrm{Cu}_{6} \mathrm{Si}_{40}$ than in the case of $\mathrm{Ba}_{8} \mathrm{Cu}_{6} \mathrm{Si}_{40}$, whereas the

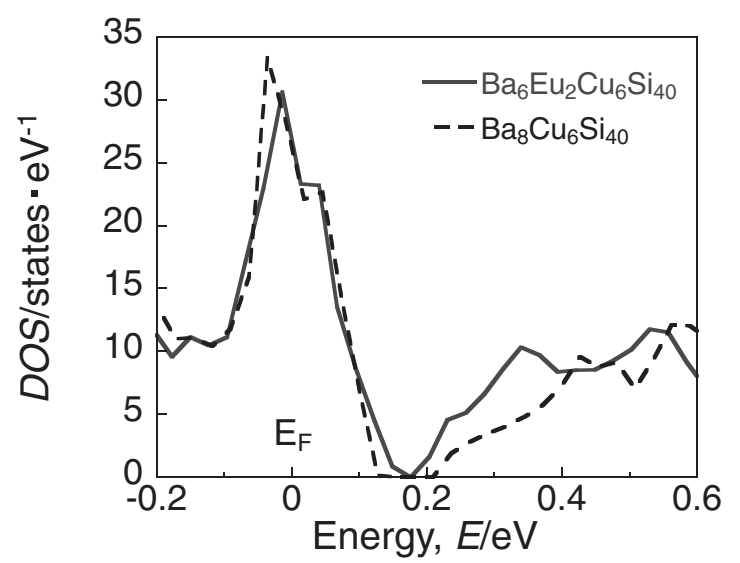

Fig. 7 Density of states (DOS) near the band edges of $\mathrm{Ba}_{8} \mathrm{Cu}_{6} \mathrm{Si}_{40}$ and $\mathrm{Ba}_{6} \mathrm{Eu}_{2} \mathrm{Cu}_{6} \mathrm{Si}_{40}$.
DOS near the top of the valence band is comparable for both systems. The increase in the effective mass and the DOS in the conduction band edge in the case of $\mathrm{Ba}_{6} \mathrm{Eu}_{2} \mathrm{Cu}_{6} \mathrm{Si}_{40}$ can be qualitatively explained in terms of the modification of the band edge structures due to the substitution of $\mathrm{Eu}$ for $\mathrm{Ba}$, based on the electronic structure calculations. Therefore, the experimentally determined increase in the electron effective mass for the $\mathrm{Ba}_{6} \mathrm{Eu}_{2} \mathrm{Cu}_{6} \mathrm{Si}_{40}$ sample is consistent with the result of the calculations.

\section{Conclusion}

Polycrystalline silicon clathrates with the nominal compositions $\mathrm{Ba}_{8-x} \mathrm{Eu}_{x} \mathrm{Cu}_{y} \mathrm{Si}_{46-y}(x=0,1,2 ; y=4,5,6)$ were prepared by a powder metallurgy technique in order to elucidate the effect of the substitution of rare-earth elements for $\mathrm{Ba}$ guests on the electronic and thermoelectric properties of the clathrates. The Ba guest was partially replaced by Eu to give compounds with $\mathrm{Ba}_{8-x} \mathrm{Eu}_{x} \mathrm{Cu}_{y} \mathrm{Si}_{46-y}$. Analysis of the transport properties of the rare-earth-doped clathrates shows that the conduction band effective mass of $\mathrm{Ba}_{8-x} \mathrm{Eu}_{x} \mathrm{Cu}_{6} \mathrm{Si}_{40}$ is larger than that of $\mathrm{Ba}_{8} \mathrm{Cu}_{6} \mathrm{Si}_{40}$. The electronic band structures of $\mathrm{Ba}_{6} \mathrm{Eu}_{2} \mathrm{Cu}_{6} \mathrm{Si}_{40}$ and $\mathrm{Ba}_{8} \mathrm{Cu}_{6} \mathrm{Si}_{40}$ were calculated by using the full-potential augmented plane waves (FLAPW) plus local orbital (LO) method. The calculation showed that the conduction band edges are modified by the substitution of $\mathrm{Eu}$ for $\mathrm{Ba}$, resulting in an increase in the density-of-states effective mass in an agreement with the experimental result.

\section{Acknowledgments}

The authors would like to thank Professor Emeritus M. Matsuura of Yamaguchi University for valuable comments on the electronic structure calculation. This work was supported by the Electric Technology Research Foundation of Chugoku, Grant-in-Aid for Scientific Research (C) No: 19560713 and (C) No: 22560708, the Asahi Glass Foundation and JST CREST.

\section{REFERENCES}

1) G. A. Slack: Proc. Mat. Res. Soc. Symp. Vol. 478, eds. by T. M. Tritt, M. G. Kanatzidis, H. B. Lyon, Jr. and G. D. Mahan, (MRS Press, Warrendale, Pennsylvania, 1997) pp. 47-54.

2) J. L. Cohn, G. S. Nolas, V. Fessatidis, T. H. Metcalf and G. A. Slack: Phys. Rev. Lett. 82 (1999) 779-782.

3) G. Nolas, J. L. Cohn, G. A. Slack and S. B. Schujman: Appl. Phys. Lett. 73 (1998) 178-180.

4) H. Anno, M. Hokazono, M. Kawamura and K. Matsubara: Proc. 22nd. Int. Conf. on Thermoelectrics (ICT2003), (IEEE, Piscataway, New Jersey, 2003) pp. 121-126.

5) M. Hokazono, M. Kawamura, H. Anno and K. Matsubara: Trans. MRS-J. 29 (2004) 2793-2796.

6) K. Akai, K. Koga, K. Oshiro and M. Matsuura: Trans. MRS-J. 29 (2004) 3647-3650.

7) H. Anno, M. Hokazono and K. Matsubara: Proc. 23rd. Int. Conf. on Thermoelectrics (ICT2004), (IEEE, Piscataway, New Jersey, 2004) \#30.

8) H. Anno, M. Hokazono, H. Takakura and K. Matsubara: Proc. 24th Int. Conf. on Thermoelectrics (ICT2005), (IEEE, Piscataway, New Jersey, 2005) pp. 102-105.

9) K. Akai, G. Zhao, K. Koga, K. Oshiro and M. Matsuura: Proc. 24th Int. Conf. on Thermoelectrics (ICT2005), (IEEE, Piscataway, New Jersey, 
2005) pp. 215-218.

10) S. Johnsen, A. Bentien, G. K. H. Madsen, M. Nygren and B. B Iversen: Proc. 24th Int. Conf. on Thermoelectrics (ICT2005), (IEEE, Piscataway, New Jersey, 2005) pp. 211-214.

11) K. Akai, K. Koga and M. Matsuura: Mater. Trans. 48 (2007) 684-688.

12) M. Hokazono, H. Anno and K. Matsubara: Mater. Trans. 46 (2005) $1485-1489$.

13) N. Jaussaud, P. Gravereau, S. Pechev, B. Chevalier, M. Ménétrier, P. Dordor, R. Decourt, G. Goglio, C. Cros and M. Pouchard: C. R. Chim. 8 (2005) 39-46.

14) S. Johnsen, A. Bentien, G. K. H. Madsen and B. B. Iversen: Chem. Mater. 18 (2006) 4633-4642.

15) H. Anno, K. Suzuki, K. Koga and K. Matsubara: Proc. 26th Int. Conf. on Thermoelectrics (ICT2007), (IEEE, Piscataway, New Jersey, 2007) pp. $243-246$

16) S. Johnsen, A. Bentien, G. K. H. Madsen, M. Nygren and B. B. Iversen: Phys. Rev. B 76 (2007) 245126.

17) N. Melnychenko-Koblyuk, A. Grytsiv, P. Rogl, M. Rotter, R. Lackner, E. Bauer, L. Fornasari, F. Marabelli and G. Giester: Phys. Rev. B 76 (2007) 195124.

18) N. Nasir, A. Grytsiv, N. Melnychenko-Koblyuk, P. Rogl, I. Bednar and E. Bauer: J. Solid State Chem. 183 (2010) 2329-2342.

19) S. Johnsen, M. Christensen, B. Thomsen, G. K. H. Madsen and B. B Iversen: Phys. Rev. B 82 (2010) 184303.

20) Y. Mudryk, P. Rogl, C. Paul, S. Berger, E. Bauer, G. Hilscher, C. Godart and H. Noël: J. Phys.: Condens. Matter 14 (2002) 7991-8004.

21) H. Anno, H. Fukushima, K. Koga, K. Okita and K. Matsubara: Proc 25th. Int. Conf. on Thermoelectrics (ICT2006), (IEEE, Piscataway, New Jersey, 2006) pp. 36-39.

22) C. L. Condron, S. M. Kauzlarich, F. Gascoin and G. J. Snyder: Chem.
Mater. 18 (2006) 4939-4945.

23) C. L. Condron, S. M. Kauzlarich and G. S. Nolas: Inorg. Chem. 46 (2007) 2556-2562

24) X. Tang, P. Li, S. Deng and Q. Zhang: J. Appl. Phys. 104 (2008) 013706.

25) K. Koga, K. Suzuki, M. Fukamoto, H. Anno, T. Tanaka and S. Yamamoto: J. Electron. Mater. 38 (2009) 1427-1432.

26) H. Anno, T. Nakabayashi and M. Hokazono: Adv. Sci. Technol. 74 (2010) 26-31.

27) K. Koga, H. Anno, K. Akai, M. Matsuura and K. Matsubara: Mater. Trans. 48 (2007) 2108-2113.

28) P. Blaha, K. Schwarz, G. K. H. Madsen, D. Kvasnicka and J. Luitz: WIEN2k, An Augmented Plane Wave Plus Local Orbitals Program for Calculating Crystal Properties. ISBN 3-9501031-1-2, (Vienna University of Technology, Austria, 2001).

29) J. P. Perdew, K. Burke and M. Ernzerhof: Phys. Rev. Lett. 77 (1996) 3865-3868.

30) X. Yan, G. Giester, E. Bauer, P. Rogl and S. Paschen: J. Electron. Mater. 39 (2010) 1634-1639.

31) Y. Li, Y. Liu, N. Chen, G. Cao, Z. Feng and J. H. Ross, Jr.: Phys. Lett. A 345 (2005) 398-408.

32) L. Yang, Y. Wang, T. Liu, T. D. Hu, B. X. Li, K. Ståhl, S. Y. Chen, M. Y. Li, P. Shen, G. L. Lu, Y. W. Wang and J. Z. Jiang: J. Solid State Chem. 178 (2005) 1773-1777.

33) C. Kittel: Introduction to Solid State Physics, 8th ed., (Wiley, New York, 2005).

34) R. D. Shannon: Acta Crystallogr. Sect. A 32 (1976) 751-767.

35) I. Fujita, K. Kishimoto, M. Sato, H. Anno and T. Koyanagi: J. Appl. Phys. 99 (2006) 093707. 